\title{
Application of at-line two-dimensional liquid chromatography-mass spectrometry for identification of small hydrophilic angiotensin I-inhibiting peptides in milk hydrolysates
}

\author{
Chris J. van Platerink • Hans-Gerd M. Janssen • \\ Johan Haverkamp
}

Received: 17 October 2007 /Revised: 18 February 2008 / Accepted: 18 February 2008 / Published online: 9 April 2008

(C) The Author(s) 2008

\begin{abstract}
A two-dimensional chromatographic method with mass spectrometric detection has been developed for identification of small, hydrophilic angiotensin I-inhibiting peptides in enzymatically hydrolysed milk proteins. The method involves the further separation of the poorly retained hydrophilic fraction from a standard $\mathrm{C}_{18}$ reversed-phase column on a hydrophilic interaction liquid chromatography (HILIC) column. The latter column is specifically designed for the separation of hydrophilic compounds. Narrow fractions collected from the HILIC column were analysed for their angiotensin I-converting enzyme (ACE) inhibiting potential in an at-line assay. Fractions showing significant inhibition of ACE were analysed by LC-MS for structure elucidation. With this method the main peptides responsible for ACE-inhibition in the hydrophilic part of a milk hydrolysate could be determined. The ACE-inhibiting peptides RP, AP, VK, EK, and EW explained more than $85 \%$ of ACE-inhibition by the hydrophilic fraction.
\end{abstract}

C. J. van Platerink $(\bowtie) \cdot$ H.-G. M. Janssen · J. Haverkamp

Advanced Measurement and Imaging,

Unilever Food and Health Research Institute,

P.O. Box 114, 3130 AC Vlaardingen, The Netherlands

e-mail: chris-van.platerink@unilever.com

C. J. van Platerink $\cdot$ J. Haverkamp

Department of Biomolecular Mass-Spectrometry,

Bijvoet Center for Biomolecular Research, Utrecht University,

Sorbonnelaan 16 ,

3584 CA Utrecht, The Netherlands

H.-G. M. Janssen

Polymer-Analysis Group, van 't Hoff Institute for Molecular

Sciences, University of Amsterdam,

Nieuwe Achtergracht 166,

1018 WV Amsterdam, The Netherlands
Keywords Angiotensin-converting enzyme · Blood pressure-lowering peptides $\cdot \mathrm{HPLC} \cdot \mathrm{MS}$. Reversed-phase $\cdot$ HILIC

\section{Introduction}

Hypertension is one of the major health problems in the western world. A variety of food ingredients that help to reduce blood pressure have been described. Particularly attractive are hydrolysed proteins from fermented milk containing specific peptides that can inhibit the angiotensin I-converting enzyme (ACE), an enzyme involved in bloodpressure regulation [1-3]. For the development of optimized anti-hypertensive food products, it is crucial to know which specific peptide(s) in the complex protein hydrolysate is (are) responsible for the ACE-inhibition.

Identification of active ingredients in complex mixtures is generally done using assay-guided repeated fractionation. For the specific case of ACE-inhibiting peptides in milkprotein hydrolysates often only part of the total activity of the product can be assigned to specific peptides [4]. A significant part of the remaining activity is present in fractions that are poorly retained by the standard reversed-phase columns used in the fractionation procedure. Nakamura et al. [1] for example could only explain part of the activity of a casein hydrolysate by the tri-peptides VPP and IPP eluting in one of the later fractions. The remaining activity was present in the unretained fraction. In our laboratory similar samples were seen to have over $30 \%$ of the total activity in the unretained fraction. Identification of the oligopeptides in this fraction was not further pursued but would have been extremely difficult because the fraction contains far too many compounds for unambiguous activity assignment. 
Moreover, there are also too many interfering compounds present in the first-eluting fractions for reliable MS identification. Similar situations are also described by other authors [5-7]. In a previous investigation we presented a new at-line method for the identification of ACE-inhibiting (oligo)peptides in hydrolysed caseinate [4]. Approximately $70 \%$ of the activity of these samples was caused by peptides nicely retained by the two reversed-phase columns used in the fractionation. Twenty percent of the activity was present in the hydrophilic fraction. The remaining $10 \%$ was caused by a large number of peptides with low ACE-inhibiting activity. Identification of the peptides in the hydrophilic fraction was impossible due to the large number of peptides present and the presence of co-eluting compounds, such as salts and sugars, that resulted in severe suppression of ionisation. Two reversed-phase columns were used in an atline 2D set-up to provide improved resolution of the very complex mixture. Unfortunately, the highly hydrophilic peptides escaped identification since they were unretained on both columns. To identify the peptides responsible for the ACE inhibition of the unretained hydrophilic fraction improved chromatographic retention and separation is required. Hydrophilic interaction chromatography (HILIC) could be an attractive way of achieving this.

The use of HILIC for separation of hydrophilic substances such as proteins, peptides, and nucleic acids was first described by Alpert in 1990 [8]. Since then HILIC has been used for the separation of many different substances, for example denaturants [9], polar oligomers [10], and pharmaceutical ingredients [11]. Many publications can be found describing the increased retention of hydrophilic peptides on HILIC columns in comparison with reversedphase columns. A detailed review is published by Yoshida [12]. Literature describing the application of reversed-phase separation in combination with HILIC chromatography is scarce. A notable exception is the compositional analysis of an enzymatic protein hydrolysate obtained from aciddeaminated wheat gluten by Schlichtherie-Cerny [13]. The hydrolysate was first fractionated by GPC. The fraction corresponding to a molecular weight range of $100-750 \mathrm{Da}$ was then further fractionated by RPLC. Finally, the peptides in the unretained peak from the RPLC column were separated and characterised by HILIC-API-MS. Using this method ten amino acids, eight di-peptides and one tri-peptide, were identified in this fraction.

In this paper we describe the development of a method for the identification of ACE inhibiting peptides in the poorly retained fractions of a reversed-phase fractionation of an enzymatically hydrolysed milk protein. The possibility of improving chromatographic resolution by using a HILIC separation as a second-dimension separation after the first reversed-phase isolation is studied. The aim of the new method is to extend the applicability of a previously developed system for the identification of ACE-inhibiting peptides in complex peptide mixtures such as protein hydrolysates [4]. The applicability of the method is demonstrated by the identification of hydrophilic ACE-inhibiting peptides in an enzymatically hydrolysed milk protein.

\section{Experimental}

\section{Chemicals}

The model peptides VPP, IPP, and LPP (purity $>98 \%$ ) were purchased from Bachum (Dübendorf, Switzerland). All other peptides were synthesised by JPT Peptide Technologies (Berlin, Germany). For HPLC analysis, acetonitrile, formic acid, and trifluoroacetic acid were purchased from Merck (Amsterdam, The Netherlands). Aqueous ammonia (Merck) was used for neutralization of the HPLC fractions. For instrument tuning PEG 300, PEG 600, and PEG 1000 were purchased from Sigma Chemicals (St Louis, MO, USA). Ammonium acetate was obtained from Merck. For the at-line assay angiotensin I-converting-enzyme (ACE) and hippuryl-histidyl-leucine (HHL) were purchased from Sigma-Aldrich Chemie (Zwijndrecht, The Netherlands). PBS buffer was purchased from Gibco (Paisley, UK). The hydrolysed milk powder was an enzymatically hydrolysed milk protein obtained from Calpis (Tokyo, Japan).

\section{Instrumentation}

All peptide separations and identifications were performed with a Waters Alliance 2795 HT HPLC coupled to a Micromass QTOF-Ultima hybrid time-of-flight mass spectrometer equipped with a lock spray option for accurate mass determination (Waters, Almere, The Netherlands). Fractions were collected in polypropylene $300-\mu \mathrm{L}$ 96-well plates (Nunc, Roskilde, Denmark) using a Mark IV fraction collector also from Waters. Solvent evaporation was performed using an Ultravap 96-well evaporation device (Porvair, Shepperton, UK). Quantification of HHL and HL in the at-line assay was performed on the QTOF instrument described above.

\section{Two-dimensional analytical separation}

The first-dimension reversed-phase separation was performed on two serially connected $150 \times 2.1 \mathrm{~mm}$ Inertsil 5 ODS3 columns, particle size $5 \mu \mathrm{m}$, operating in the gradient mode (Varian, Middelburg, The Netherlands). The guard column was a $20 \times 3.9 \mathrm{~mm}$ SymmetryShield RP8 column packed with 5- $\mu \mathrm{m}$ particles (Waters, Etten-Leur, The Netherlands). Mobile phase A consisted of $0.1 \%$ TFA in Milli-Q water. Mobile phase B consisted of $0.1 \%$ TFA in 
acetonitrile. The initial eluent composition was $100 \%$ A. After a $5 \mathrm{~min}$ hold a linear gradient was started to $5 \% \mathrm{~B}$ in $15 \mathrm{~min}$, followed by a linear gradient to $70 \% \mathrm{~B}$ in $75 \mathrm{~min}$. Finally, mobile phase composition was programmed to $99 \%$ $\mathrm{B}$ in $1 \mathrm{~min}$ and kept at $99 \%$ B for another $4 \mathrm{~min}$. At the end of the gradient the eluent composition was reduced to $100 \%$ $\mathrm{A}$ in $6 \mathrm{~min}$ and the system was allowed to re-equilibrate for $14 \mathrm{~min}$. The total run time was $120 \mathrm{~min}$. The eluent flow rate was $0.2 \mathrm{~mL} \mathrm{~min}^{-1}$ and the column temperature was $60^{\circ} \mathrm{C}$. In-house experiments revealed that at this temperature isomeric peptides such as IPP and LPP are separated. UV detection was performed at $215 \mathrm{~nm}$ and $254 \mathrm{~nm}$. Fractions of $200 \mu \mathrm{L}$ were collected in 96 -well plates. After neutralization and solvent evaporation the residues were reconstituted in $50 \mu \mathrm{L}$ of an 80:20 mixture of solvents $\mathrm{A}$ and $\mathrm{B}$ for the second-dimension HILIC analysis.

The second dimension HILIC analysis was performed on a $150 \times 2.1 \mathrm{~mm}$ HILIC Atlantis column with a particle size of $3 \mu \mathrm{m}$ (Waters, Etten-Leur, The Netherlands). Here solvent A consisted of $0.1 \%$ formic acid in acetonitrile and solvent $\mathrm{B}$ of $10 \mathrm{mmol} \mathrm{L}^{-1}$ aqueous ammonium acetate solution $+0.1 \%$ formic acid in Milli-Q water. The separation was performed at $40^{\circ} \mathrm{C}$, the maximum temperature specified by the manufacturer, and a flow rate of $0.2 \mathrm{~mL} \mathrm{~min}^{-1}$. The initial eluent composition was $95 \%$ A. A linear gradient was used to $70 \% \mathrm{~B}$ in $30 \mathrm{~min}$, followed by a linear gradient to $90 \% \mathrm{~B}$ in $5 \mathrm{~min}$ where it was kept for another $5 \mathrm{~min}$. At the end of the run the eluent was reduced to $95 \%$ $\mathrm{C}$ in $2 \mathrm{~min}$. The eluent flow was then increased to $0.3 \mathrm{~mL}$ $\min ^{-1}$ in $1 \mathrm{~min}$. This flow rate was maintained for another $7 \mathrm{~min}$. Finally the flow was reduced to $0.2 \mathrm{~mL} \mathrm{~min}^{-1}$ in $1 \mathrm{~min}$. and the system was allowed to equilibrate for $3 \mathrm{~min}$. The total run time was $54 \mathrm{~min}$. $45 \mu \mathrm{L}$ of each fraction collected from the ODS3 column was injected. At the outlet of the second dimension HILIC column fractions of $200 \mu \mathrm{L}$ were collected in 96-well plates. The fractions were neutralized, evaporated, and transferred to the activity assay (next section).

\section{At-line Matsui assay}

ACE inhibition by the collected fractions was measured in a 96-well plate assay according to the at-line method described in an earlier publication [1]. The method is based on the conversion of hippuryl-histidyl-leucine (HHL) into hippurate $(\mathrm{H})$ and histidyl-leucine (HL) by the angiotensin I-converting enzyme (ACE). Briefly, after evaporation of the eluent the fractions were reconstituted in $50 \mu \mathrm{L}$ PBS buffer and vortex mixed for $1 \mathrm{~min}$. This solution $(40 \mu \mathrm{L})$ was used for the at-line assay. Percentage inhibition was calculated from the peak areas of HHL and $\mathrm{H}$ at $280 \mathrm{~nm}$. For the active fractions the remaining $10 \mu \mathrm{L}$ was used for identification of the peptides.
Structural identification of ACEI peptides

Peptide identification was performed on the QTOF MS instrument using HPLC-MS and MS-MS in the accurate mass mode. Fractions collected after the second dimension that showed activity were separated on the HILIC column now coupled to the MS using the gradient described above. The source and desolvation temperatures were $100^{\circ} \mathrm{C}$ and $300^{\circ} \mathrm{C}$, respectively. The cone and desolvation gas flows were $100 \mathrm{~L} \mathrm{~h}^{-1}$ and $800 \mathrm{~L} \mathrm{~h}^{-1}$, respectively. The capillary voltage was $4 \mathrm{kV}$ and the cone voltage $35 \mathrm{~V}$. The collision energy was $10 \mathrm{eV}$ in full-scan mode and $25 \mathrm{eV}$ in MS-MS mode. The collision gas was argon and the analyser pressure was $4 \times 10^{-5} \mathrm{mbar}$. In the lock spray probe a mixture of PEG 300, PEG 600, and PEG 1000 dissolved in $10 \mathrm{mmol} \mathrm{L}^{-1}$ ammonium acetate in methanol-water $1: 1(v / v)$ at concentrations of $0.01,0.02$, and $0.04 \mu \mathrm{g} \mathrm{mL}^{-1}$, respectively, was used. The reference flow was $5 \mu \mathrm{L} \mathrm{m^{-1 }}$. Spectra were recorded at a resolution of 10,000. Masslynx software (Waters) was used for data acquisition and evaluation.

\section{Results and discussion}

In a reversed-phase fractionation of a protein hydrolysate a significant percentage of the activity can be present in the unretained hydrophilic fraction. To be able to calculate the contribution of this fraction of our milk hydrolysate to the total activity, an ACE-inhibition profile of the entire product was produced. To this end $20 \mu \mathrm{L}$ of a $20 \mathrm{mg} \mathrm{mL}^{-1}$ solution of the milk hydrolysate in solvent A was injected on to the $300 \mathrm{~mm}$ ODS 3 column. Fractions of $200 \mu \mathrm{L}$ each were collected from 0 to $65 \mathrm{~min}$, with an interval time of $1 \mathrm{~min}$, in a 96 well plate. The ACE inhibition of each fraction was determined. Figure 1a shows the MS TIC of the fermented milk and Fig. 1b shows the activity profile of the same analysis. From the data in Fig. $1 b$ it was calculated that the hydrophilic compounds in fractions 6 to 15 represent approximately $25 \%$ of the total ACE inhibition. MS-MS showed that the high activity in fractions 27 to 31 resulted from the known ACE inhibiting peptides IPP and LPP. The activity in fractions 21 to 23 resulted from the peptide VPP. These peptides have been identified to be the main contributors to the ACE-inhibition of a Lactobacillus helveticus-fermented milk [2] and represent $40 \%$ of the total ACE inhibition. The remaining activity between fractions 16 and 40 is most likely caused by a mixture of ACE-inhibiting peptides of different chain lengths. This is still under investigation. In the region from fraction 6 to fraction 15 a large number of peptides co-elute and the spectra of the fractions are highly complex. Figure 2, for example, shows the mass spectrum of fraction 7 collected from the first dimension ODS 3 columns and the ion traces 


\section{a}

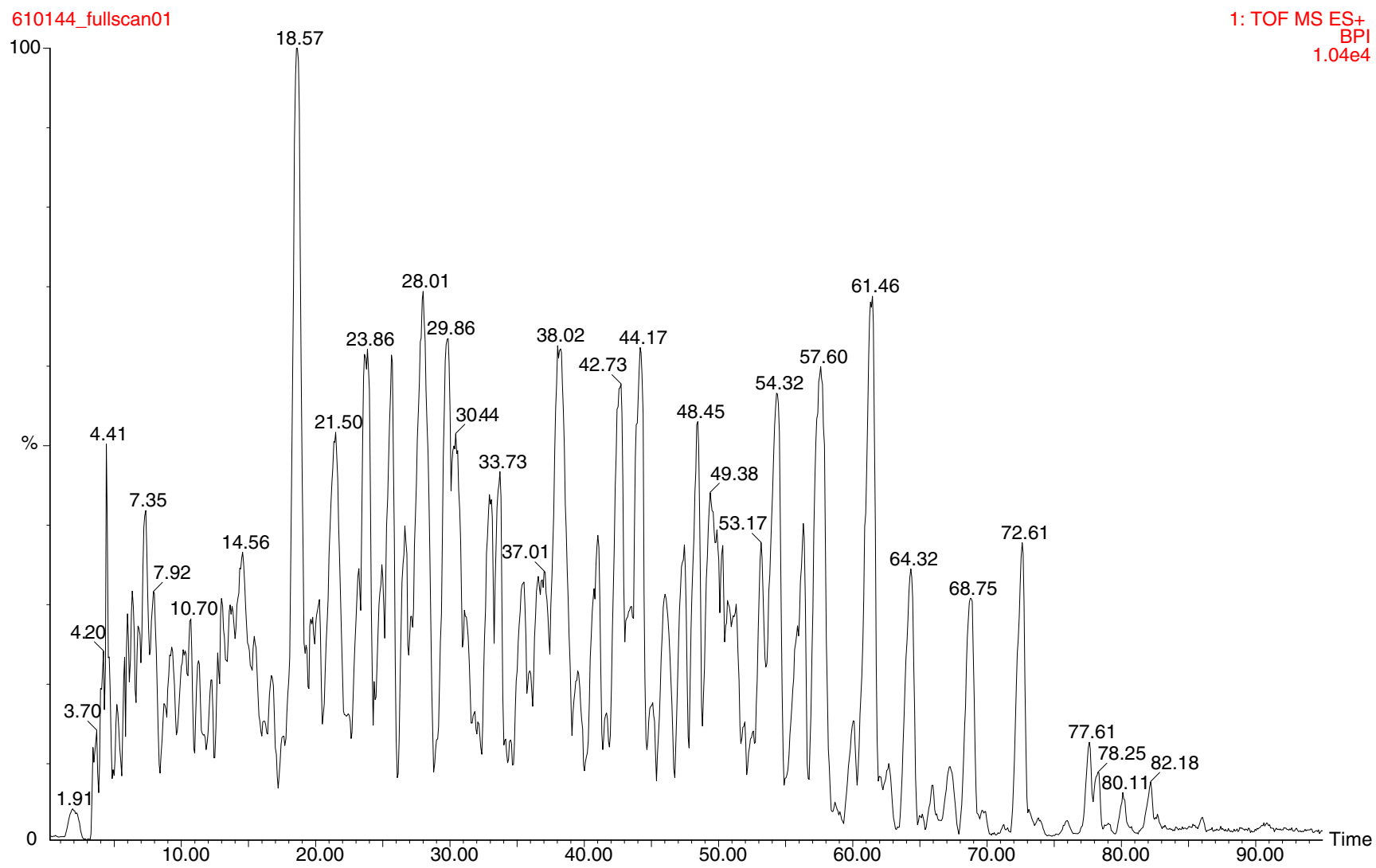

b

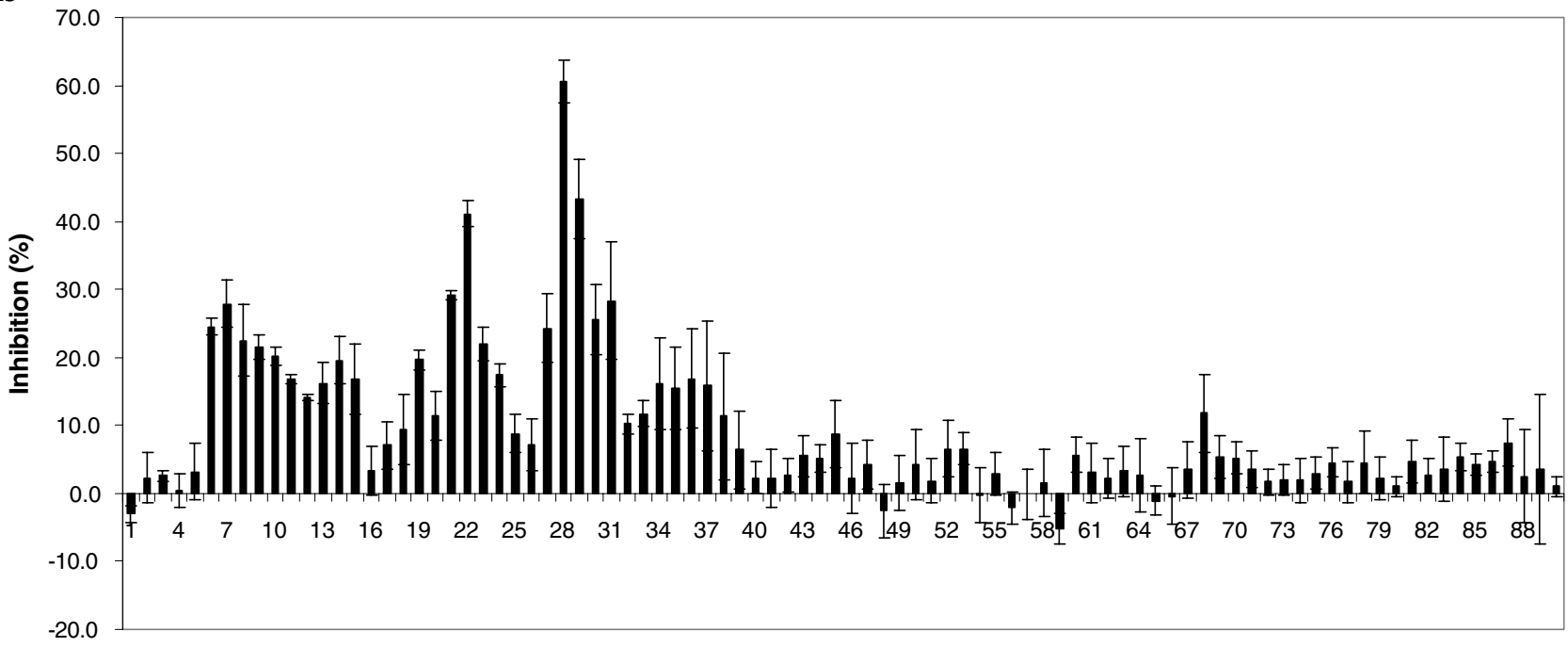

\section{Fraction no}

Fig. 1 LC separation of a $20 \mathrm{mg} \mathrm{mL}^{-1}$ solution of the milk hydrolysate powder on the ODS-3 reversed-phase column. a MS-TIC chromatogram. b Activity profile. Error bars indicate the standard deviation $(n=3)$. Fraction volume $200 \mu \mathrm{L}$

of three of the ACE-inhibiting peptides discussed later in this manuscript. At least 16 ions can be observed with intensities above $10 \%$ of the base peak, all representing different peptides. In order to be able to assign the measured activity to one or more of these peptides a further separation in an additional chromatographic dimension is required. To achieve this, fractions collected from the firstdimension ODS column were injected on the second dimension HILIC column. Again $200-\mu \mathrm{L}$ fractions were collected in 96-well plates. After neutralization and evaporation the residues were reconstituted in $50 \mu \mathrm{L}$ Milli-Q water. Of this, $40 \mu \mathrm{L}$ was used for ACE inhibition testing, 


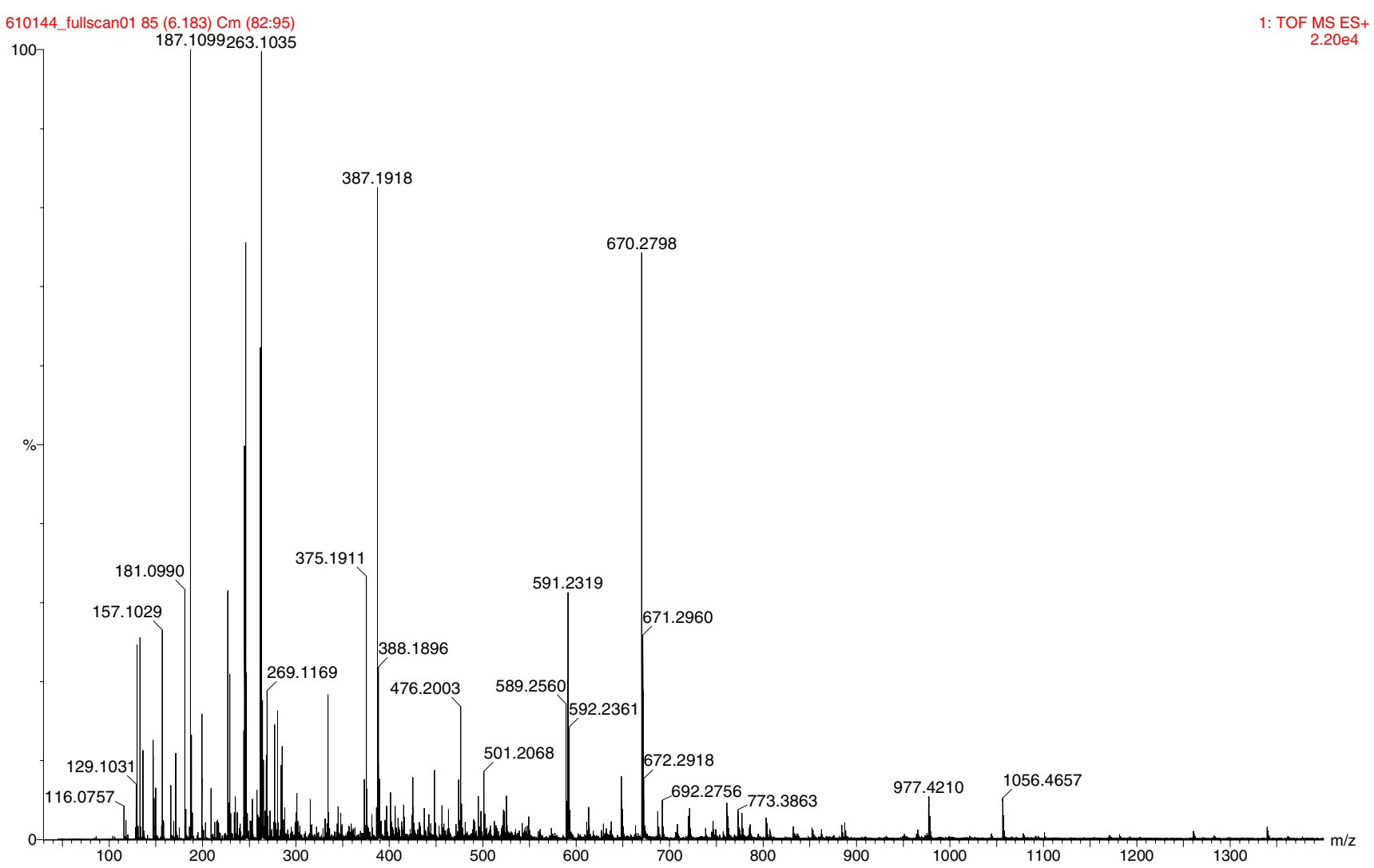

Fig. 2 Mass spectrum of fraction 7 collected from the first-dimension ODS3 column

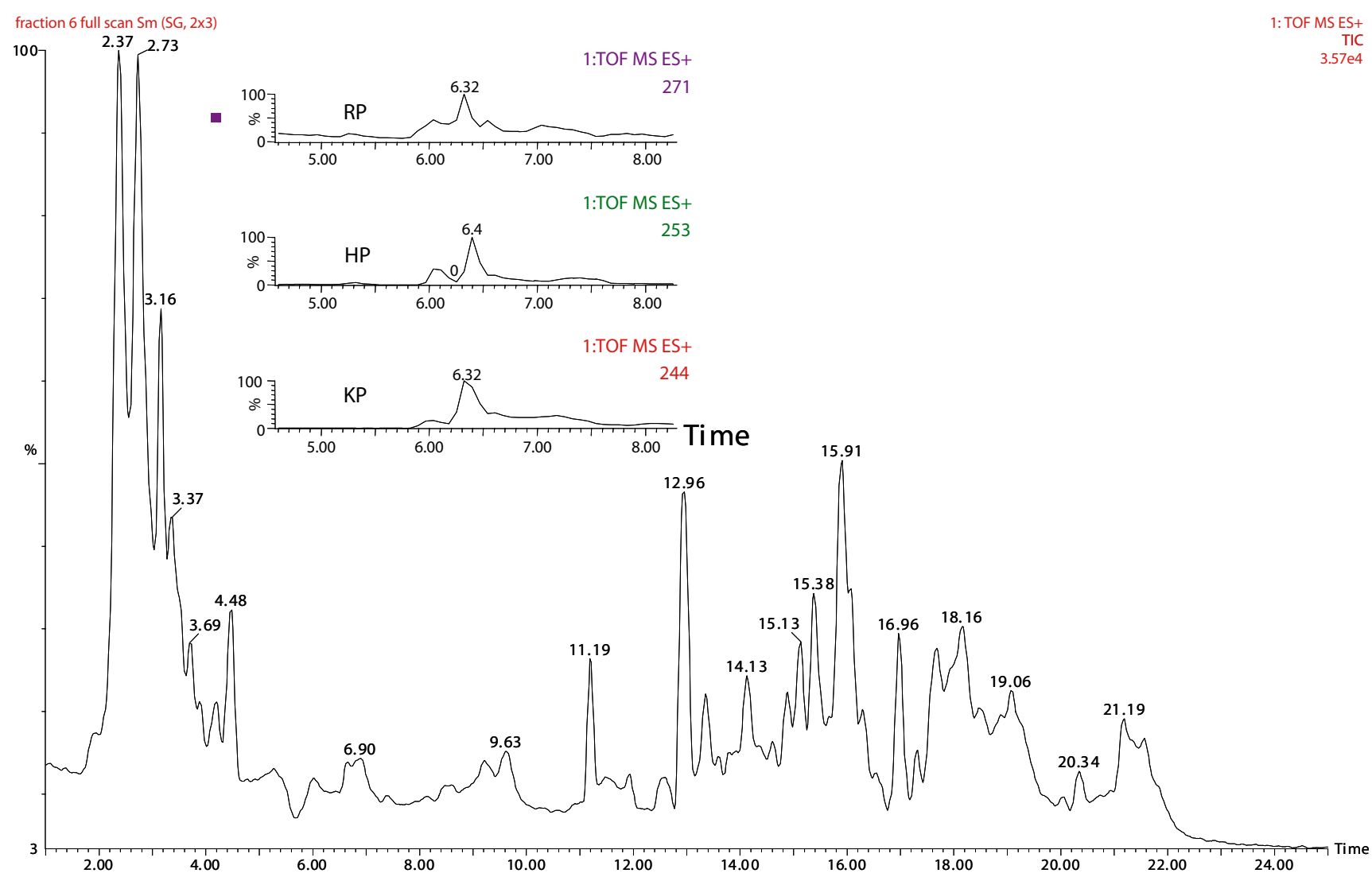

Fig. 3 MS-TIC of fraction 7 from the ODS3 column analysed on the HILIC column. The inset shows the selected ion traces of three of the most active peptides 
Fig. 4 ACEI profile of fraction 7 from the ODS3 column analysed on the HILIC column

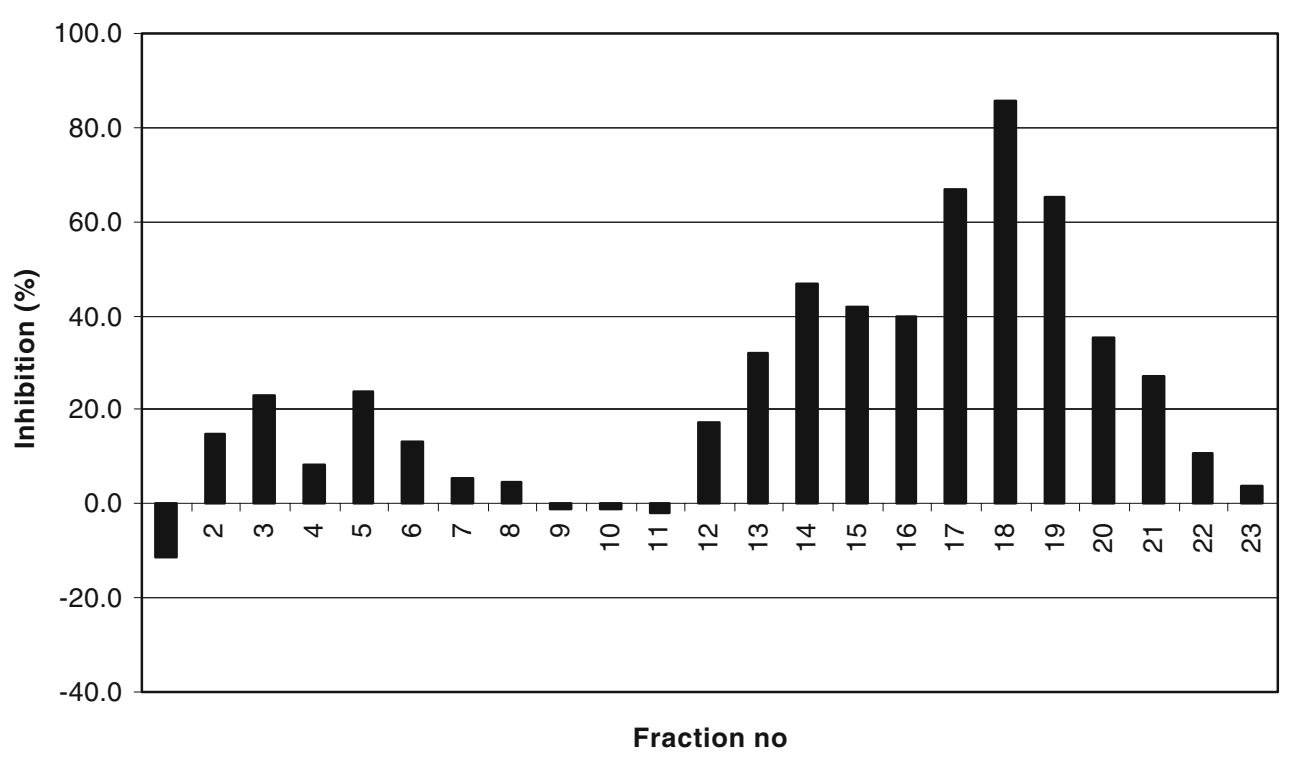

the remaining $10 \mu \mathrm{L}$ for MS identification. As an example of the results of these experiments, Fig. 3 shows the TIC chromatogram obtained from full-scanning analysis of fraction 7 of the ODS3 columns, now separated on the second dimension HILIC column. The TIC chromatogram clearly shows that the composition of this fraction is indeed very complex. To identify the peptide(s) responsible for the ACE-inhibition, the fractions collected in the 96-well plate were subjected to the ACE-inhibition assay. Figure 4 displays the activity distribution of ODS fraction 7. The data in Fig. 4 are corrected for the background recorded using a blank gradient, i.e. a gradient without injection. Blank analysis of the HILIC column showed slightly negative values compared with a reference of pure PBS. The reason for these negative responses is still unknown. The results in Fig. 4 clearly show the strong activity in

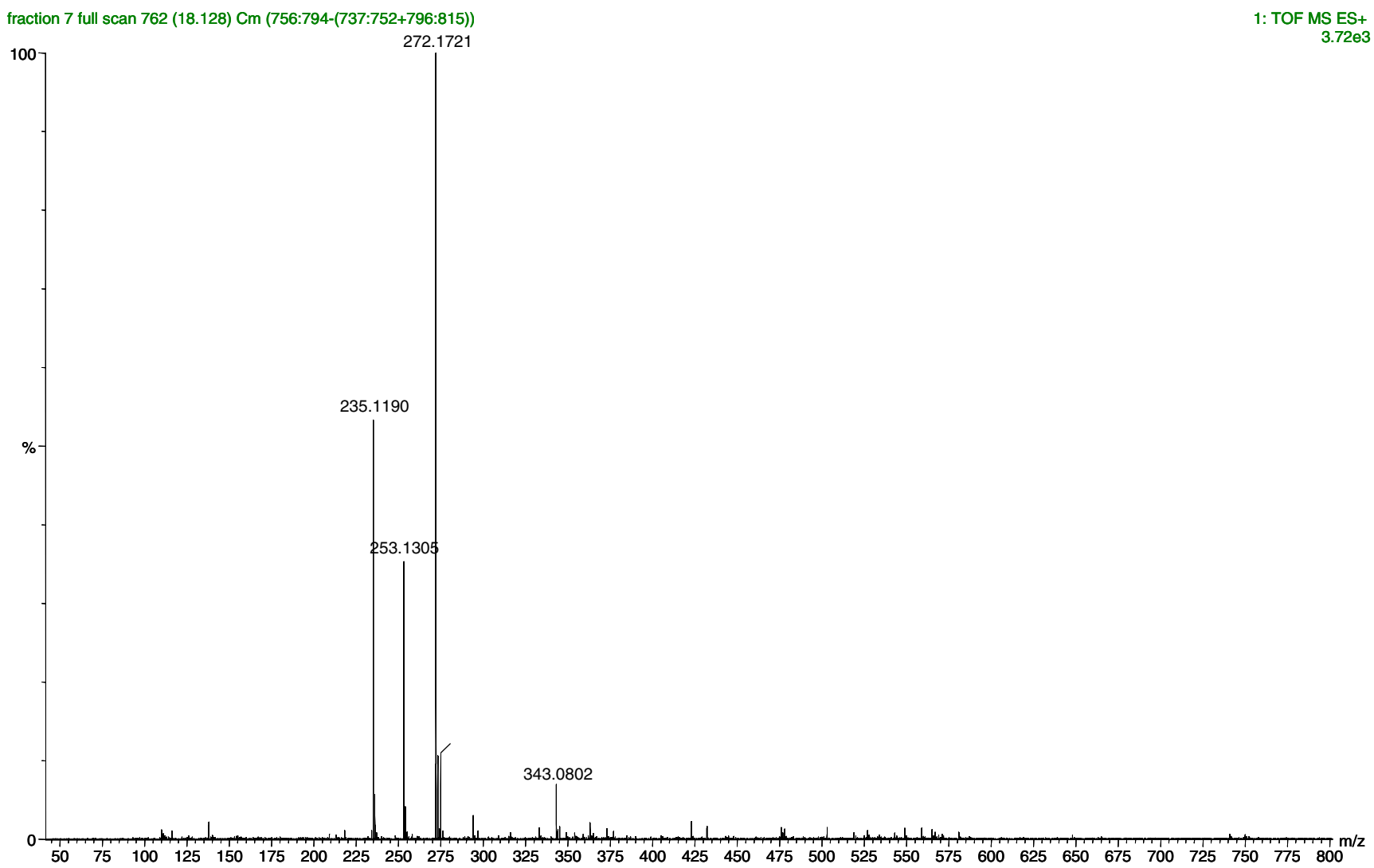

Fig. 5 Mass spectrum of fraction 18 collected from the HILIC column 
Fig. 6 Three-dimensional display of the ACEI distribution of the fractions collected from the ODS 3 column and the HILIC column

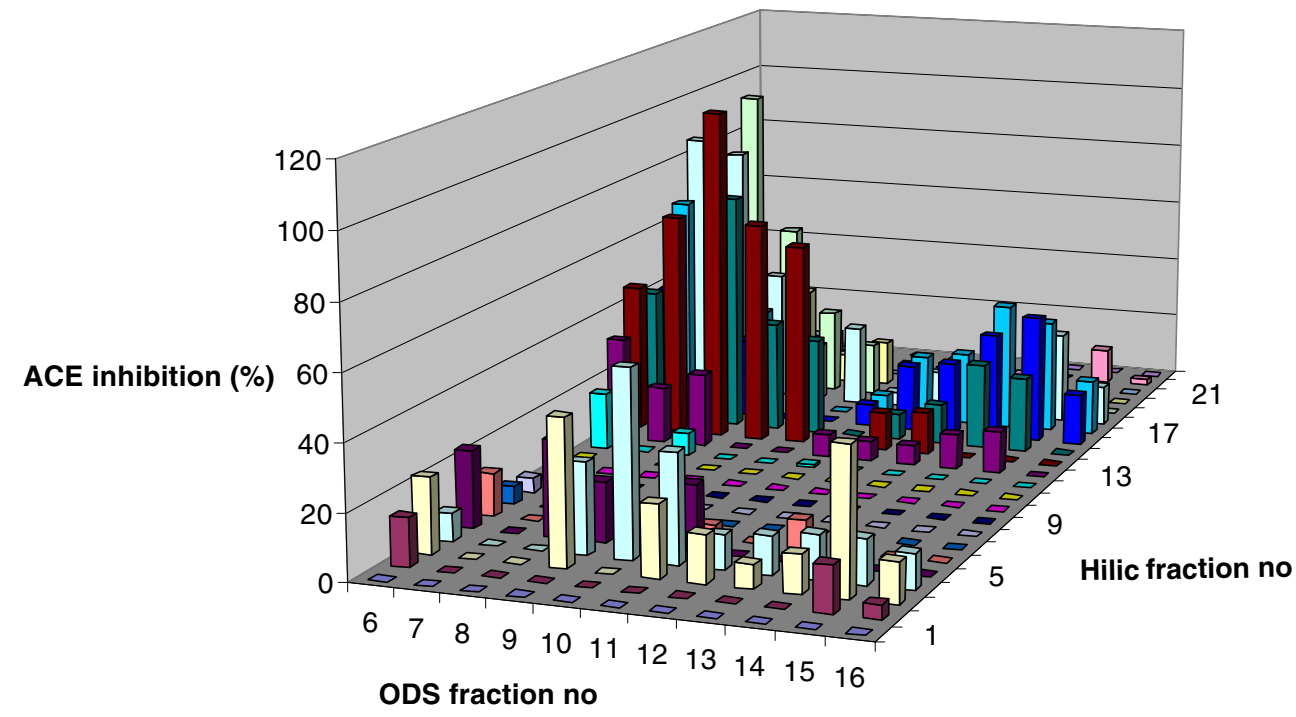

HILIC fractions 17 to 19 and somewhat lower activity in fractions 12 to 16 from the HILIC column. LC-MS separations were performed on these fractions and the MS data were searched for peptides in the two active regions. In Fig. 5 the mass spectrum of fraction 18 is given. In the spectrum three abundant ions can be observed. A library

Table 1 Peptides identified in fractions 6 to 15 of the ODS3 column, analysed on the HILIC column

\begin{tabular}{|c|c|c|c|c|c|c|c|c|c|c|c|}
\hline $\begin{array}{l}\text { elution } \\
\text { (min) } \\
\text { time }\end{array}$ & $\begin{array}{l}\text { peptide } \\
\text { sequence }\end{array}$ & $\begin{array}{l}\text { IC50 } \\
\text { value } \\
(\mu \mathrm{M}) \\
\text { literature }\end{array}$ & $\begin{array}{l}\text { Literature } \\
\text { reference }\end{array}$ & $\begin{array}{l}\text { Inhibition } \\
\text { at } 20 \mu \mathrm{M} \\
(\%)\end{array}$ & $\begin{array}{l}\text { peak } \\
\text { area } \\
\text { (counts) }\end{array}$ & $\begin{array}{l}\text { elution } \\
\text { time } \\
(\mathrm{min})\end{array}$ & $\begin{array}{l}\text { peptide } \\
\text { sequence }\end{array}$ & $\begin{array}{l}\text { value } \\
(\mu \mathrm{M}) \\
\text { literature }\end{array}$ & $\begin{array}{l}\text { Literature } \\
\text { reference }\end{array}$ & $\begin{array}{l}\text { Inhibition } \\
20 \mu \mathrm{M} \\
(\%)\end{array}$ & $\begin{array}{l}\text { peak } \\
\text { area } \\
\text { (counts) }\end{array}$ \\
\hline 11.64 & $\mathbf{F}$ & n.r. & & & 83 & 16.34 & FP & 1215.7 & 13 & n.m. & 631 \\
\hline 11.90 & $\mathbf{Y}$ & n.r. & & & 2274 & 16.41 & HSM & n.r. & & & 656 \\
\hline 12.02 & EI & n.r. & & 38.2 & 2221 & 16.43 & EPF & n.r. & & & 186 \\
\hline 12.36 & IE & n.r. & & 3.7 & 4591 & 16.43 & DKI & n.r. & & & 187 \\
\hline 12.40 & YP & 720 & 13 & n.m. & 58 & 16.52 & KY & $1.63,7.8,13$ & $16,13,17$ & n.m. & 13 \\
\hline 12.59 & EV & n.r. & & 25.4 & 622 & 16.66 & VYP & 288 & 13 & & 125 \\
\hline 12.59 & VE & n.r. & & 41.0 & 22 & 17.00 & EW & n.r. & & 65.1 & 1578 \\
\hline 12.59 & IP & 129 & 13 & 17.7 & 100 & 17.22 & VK & 12.9 & 13 & 57.2 & 167 \\
\hline 12.84 & VP & 575 & 13 & 45.9 & 801 & 17.23 & ER & n.r. & & n.m. & 236 \\
\hline 13.21 & $\mathbf{E}$ & n.r. & & n.m. & 288 & 17.30 & SGY & n.r. & & & 624 \\
\hline 13.26 & TE & n.r. & & 26.0 & 344 & 17.35 & ME & n.r. & & 24.6 & 42 \\
\hline 13.44 & LQ & n.r. & & 11.2 & 748 & 17.55 & $\mathbf{K}$ & n.r. & & n.m. & 497 \\
\hline 13.74 & $\mathbf{K P}$ & $16,22,30$ & 13,15 & 33.7 & 144 & 17.61 & EK & n.r. & & 41.8 & 337 \\
\hline 13.81 & VNE & n.r. & & & 1378 & 17.84 & $\mathbf{R E}$ & n.r. & & n.m. & 166 \\
\hline 14.08 & $\mathrm{LN}$ & n.r. & & 14.7 & 271 & 17.86 & $\mathbf{K E}$ & n.r. & & 13.4 & 83 \\
\hline 14.10 & $\mathbf{Q}$ & n.r. & & n.m. & 511 & 17.89 & KV & 33 & & n.m. & 235 \\
\hline 14.10 & QD & n.r. & & n.m. & 791 & 18.04 & VVR & n.r. & & & 114 \\
\hline 14.28 & TDVEN & n.r. & & & 2019 & 18.08 & HP & n.r. & & 11.1 & 1427 \\
\hline 14.50 & PT & n.r. & & 3.1 & 1001 & 18.18 & KVP & n.r. & & & 45 \\
\hline 14.56 & NVP & n.r. & & & 2744 & 18.24 & VPQ & n.r. & & & 505 \\
\hline 14.61 & YQ & n.r. & & n.m. & 36 & 18.63 & $\mathbf{R P}$ & $21,91,182$ & 13 & 36.4 & 1340 \\
\hline 14.64 & SPP & n.r. & & & 335 & 18.97 & PH & n.r. & & 0.0 & 306 \\
\hline 14.72 & TQ & n.r. & & 0.0 & 175 & 19.03 & QP & n.r. & & n.m. & 402 \\
\hline 14.86 & $\mathbf{A H}$ & n.r. & & 7.3 & 101 & 19.11 & KP & $16,22,30$ & 13,15 & 33.6 & 144 \\
\hline 14.91 & PP & 2284.7 & 18 & 0.0 & 1759 & 19.22 & APK & n.r. & & n.m. & 266 \\
\hline 15.01 & $\mathbf{A P}$ & 29,269 & 13,10 & 11.4 & 811 & 20.18 & VRG & n.r. & & n.m. & 313 \\
\hline 15.18 & PQ & n.r. & & 0.0 & 1041 & 20.47 & $\mathrm{HK}$ & n.r. & & 0.0 & 398 \\
\hline
\end{tabular}

The sequences of the bold printed peptides were confirmed by MS-MS analyses of reference peptides, n.r., not reported in the literature; n.m., not measured 
Fig. 7 Distribution of the ACEinhibiting activity, calculated from Table 1, in hydrophilic fractions 5 to 10 collected from the ODS3 column

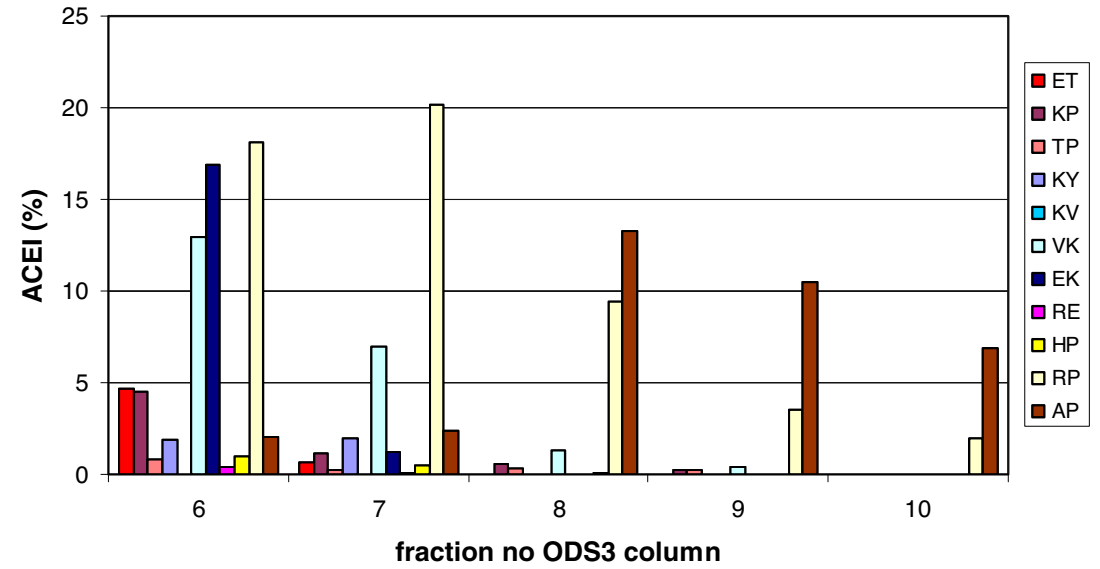

search and MS-MS measurements revealed that $\mathrm{m} / \mathrm{z}$ 272.1721 represents the molecular ion of the di-peptide RP (-0.7ppm), while $m / z 253.1190$ represents the molecular ion of HP $(-2.1 \mathrm{ppm})$ and $\mathrm{m} / z 235.1305$ the loss of water from $\mathrm{m} / \mathrm{z} 253.1190$. Identification of the peptides in the remaining fractions of the HILIC column showed that fraction 7 of the first-dimension ODS3 column consisted of three free amino acids, 19 di-peptides and 2 tri-peptides while six compounds remained unidentified. The positively identified amino acids were $\mathrm{E}, \mathrm{Q}$, and $\mathrm{K}$ and the di-peptides were QD, KY, ER, RE, KP, HP, RP, AP, VK, EK, EW, and PH. The di-peptides ET, TP, TQ, PQ, KV, KE, and HK and the tri-peptides APK and VRG were tentatively identified. Structure confirmation was based on elution time, measured exact mass (error $<5 \mathrm{ppm}$ ) and MS-MS fragmentation pattern compared with those of the model compounds. Using this method the remaining hydrophilic fractions 5 to 15 collected from the ODS3 column were also analysed in the 2D mode. In Fig. 6 a three-dimensional plot of the activity distribution over the fractions of the two columns is given. In total, five amino acids, 35 di-peptides, 13 tripeptides, one penta-peptide and 18 not yet identified compounds were found. The identities of all amino acids and the sequence of 27 di-peptides were again confirmed by use of model compounds. Table 1 lists the sequences of the identified peptides together with their reported IC50 values and ACE inhibition data at $20 \mu \mathrm{mol} \mathrm{L} \mathrm{L}^{-1}$ established in house (Foltz et al. manuscript in preparation). For peptides for which no model compounds were available, identification was based solely on the fragmentation pattern in MS-MS.

To verify whether the identified peptides indeed fully explain the measured activity of the hydrophilic fraction the concentration of all peptides should be determined. Next a mixture should be prepared which is then analysed using the two-dimensional method described in this article. The ACE-inhibition profile of this mixture should be identical with that of the sample. Such an experiment will hardly be feasible because it requires the availability of all the components. To estimate of the completeness of identification, the contribution of each peptide was estimated from the measured peak area and the IC50 value obtained from literature or from unpublished in-house data. To estimate the contribution of an individual peptide the following relationship was used: $\mathrm{CA} \approx A_{\mathrm{p}} / \mathrm{IC} 50_{\mathrm{p}}$. In this equation CA represents the contribution of the peptide to the measured ACE-inhibition, $A_{\mathrm{p}}$ the peak area, and IC $50_{\mathrm{p}}$ the IC50 value of the peptide. Clearly this proportionality equation is only approximate as it assumes that the MS response for all peptides is identical. When both the peak area and the IC50 value are taken into consideration it can be concluded that the di-peptides AP, RP, VK, and EK are the main peptides responsible for the measured ACE-inhibition of the hydrophilic fractions 6 to 10 collected from the ODS3 column
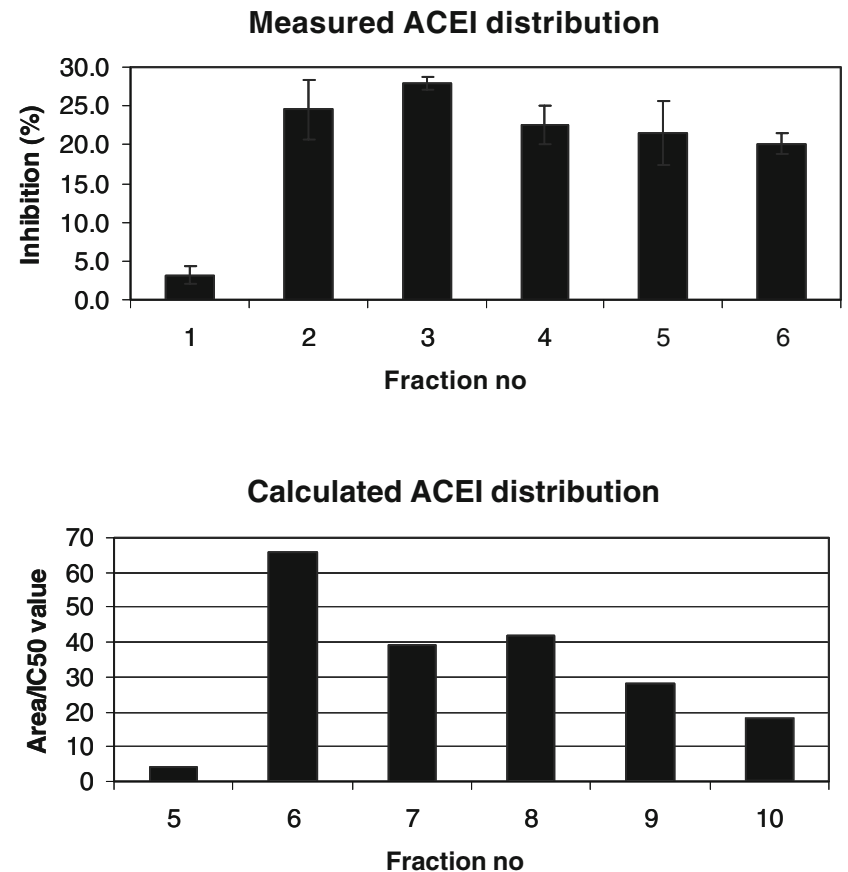

Fig. 8 Calculated (bottom) and measured (top) ACE inhibition profiles 
(Fig. 7). In Fig. 8 the activities of all peptides in each fraction are summarized and the profile is compared with that of the measured profile. The two profiles are similar. The differences between the graphs can be explained from the fact that no correction was applied for differences in MS responses of the various peptides.

The remaining fractions 11 to 15 of the ODS 3 column were analysed in the same way as fractions 6 to 10 . These analyses showed that the peptide EW is responsible for the major part of the ACE-inhibition measured in these fractions. In total, the five peptides identified in the fractions 6 to 15 are responsible for approximately $85 \%$ of the activity measured in the hydrophilic fractions. The most important contribution is that of the di-peptide RP, which is responsible for $34 \%$. Together with the peptides VPP, IPP, and LPP now approximately $65 \%$ of the total activity of the product has been explained. The remaining 35\% is distributed over a large number of peptides with relatively low overall activities.

When compiling the list of published IC50 values for the peptides identified in this study in some cases large differences were seen for the IC50 values of prolinecontaining peptides in different publications. The reported IC50 values for AP, for example, vary between 29 and $269 \mu \mathrm{mol} \mathrm{L}^{-1}$ [14]. This large difference might be caused by variations in the cis-to-trans ratio of the proline present in synthetic model compounds as a result of differences in the synthetic routes (Fmoc or Boc), as was shown for the peptide DKIHP by Gómez-Ruiz [15]. In our calculations the trans-Pro value of $29 \mu \mathrm{mol} \mathrm{L} \mathrm{L}^{-1}$ for AP was used, because trans-Pro is known to be dominant in natural products [15]. Many of the identified di-peptides were found in milk hydrolysates for the first time. For most of the newly identified ACE active peptides it is actually the first time they are reported at all. The long list of newly identified peptides found here clearly demonstrates the potential of the two dimensional separation approach of HILIC and reversed-phase HPLC described here.

\section{Conclusions}

Two-dimensional liquid chromatography in combination with mass spectrometry was successfully used for identification of poorly retained peptides present in enzymatically hydrolysed milk protein. A standard $\mathrm{C}_{18}$ reversed-phase column was used for the first separation followed by a second dimensional separation on a HILIC column. This two-dimensional procedure significantly improves the separation of hydrophilic peptides that elute almost unretained on a reversed-phase column and co-elute with numerous other compounds such as carbohydrates and salts. These compounds suppress the MS ionization and complicate identification. The method enabled the identification of hydrophilic peptides in complex mixtures. In the hydrophilic fraction of the milk hydrolysate investigated 71 compounds were found, including five free amino acids, 35 di-peptides, 12 tri-peptides, one penta-peptide, and 18 not yet identified compounds. Five peptides, RP, AP, VK, EK, and EW were responsible for approximately $85 \%$ of the measured activity of the hydrophilic fraction; of these RP made the highest contribution of $34 \%$. None of the five peptides has, to our knowledge, been reported earlier in milk hydrolysates or related products such as yogurt or cheese. Most of the peptides involved remained undetected in single-dimensional chromatography.

Open Access This article is distributed under the terms of the Creative Commons Attribution Noncommercial License which permits any noncommercial use, distribution, and reproduction in any medium, provided the original author(s) and source are credited.

\section{References}

1. Nakamura Y, Yamamoto N, Sakai K, Okubo A, Yamazaki S, Takano T (1995) J Dairy Sci 78:777-783

2. Lopez-Exposito I, Quiros A, Amigo L et al (2007) Lait 87:241249

3. Tsai JS, Chen TJ, Pan BS et al (2008) Food Chem 106:552-558

4. van Platerink CJ, Janssen HGM, Haverkamp J (2007) J Chromatogr B 846:147-154

5. Robert M-C, Razaname A, Mutter M, Juillerat MA (2004) J Agric Food Chem 52:6923-6931

6. Maeno M, Yamamoto N, Takano T (1996) J Dairy Sci 79:13161321

7. Gómez-Ruiz JA, Taborda G, Amigo L, Reccio I, Ramos M (2006) Eur Food Res Technol 223:595-601

8. Alpert AJ (1990) J Chromatogr 499:177-196

9. Daunoravicius Z, Juknaite I, Naujalis E (2006) Chromatographia 63:373-377

10. Jandera P, Fischer J, Lahovska H, Novotna K, Cesla P, Kolarova L (2006) J Chromatogr A 1119:3-10

11. Wang XD, Li WY, Rasmussen HT (2005) J Chromatogr A 1083:58-62

12. Yoshida T (2004) J Biochem Biophys Methods 60:265-280

13. Schlichtherie-Cerny H, Affolter M, Cerny C (2003) Anal Chem 75:2349-2354

14. Wu J, Aluko RE, Nakai S (2006) J Agric Food Chem 54:732-738

15. Gómez-Ruiz JA, Recio I, Belloque J (2004) J Agric Food Chem 52:6315-6319 